\title{
Antifungal Activity and Possible Mode of Action of Borate Against Colletotrichum gloeosporioides on Mango
}

Xue-Qun Shi, Key Laboratory of Photosynthesis and Environmental Molecular Physiology, Institute of Botany, the Chinese Academy of Sciences, Beijing 100093, China, and Graduate School of Chinese Academy of Sciences, Beijing 100049, China; Bo-Qiang Li, Guo-Zheng Qin, and Shi-Ping Tian, Key Laboratory of Photosynthesis and Environmental Molecular Physiology, Institute of Botany, the Chinese Academy of Sciences, Beijing 100093, China

\begin{abstract}
Shi, X.-Q., Li, B.-Q., Qin, G.-Z., and Tian, S.-P. 2011. Antifungal activity and possible mode of action of borate against Colletotrichum gloeosporioides on mango. Plant Dis. 95:63-69.

The effect of potassium tetraborate on germination of conidia of Colletotrichum gloeosporioides, and postharvest rot of mango were studied. An application of $\mathrm{K}_{2} \mathrm{~B}_{4} \mathrm{O}_{7}$ to mango trees at flowering increased fruit set and decreased the incidence of anthracnose on harvested fruit. The effects of borate on the germination, nuclear division, endocytosis, and ultrastructure of conidia of C. gloeosporioides were studied using light, confocal, and transmission electron microscopy. The results showed that borate inhibited germination and germ tube elongation, delayed

nuclear division, and impaired endocytosis of $C$. gloeosporioides conidia. Ultrastructural abnormalities also occurred in conidia treated with borate, and these included an increase in numbers of vacuoles, cytoplasmic disintegration, mitochondria degradation, and plasmolysis. These results suggest that borate can serve as a potential alternative to synthetic fungicides for the control of the postharvest disease of mango fruit caused by $C$. gloeosporioides.
\end{abstract}

Mango (Mangifera indica L.) is a popular tropical fruit and is frequently affected by anthracnose caused by Colletotrichum gloeosporioides (Penz.) Penz. \& Sacc. The disease is one of the most serious postharvest diseases of mango fruit and causes great hardship (8). Because C. gloeosporioides infects mango flowers, leaves, and fruit in the field, one of the strategies to manage the disease is to prevent infections during florescence and fruit development (11). Postharvest losses to anthracnose are reduced by application of fungicides before harvest and by application of hot water dips, fungicides, and antagonists after harvest $(9,20,25)$.

Recent reports have indicated that certain organic and inorganic salts inhibit the growth of many pathogens $(1,6,12,13)$, and borates have been used extensively in industry and agriculture as a safe method for the control of algae, fungi, and termites $(4,10,16,22)$. In an in vitro study, we found that borate inhibited conidial germination and germ tube elongation of the plant-pathogenic fungus Penicillium expansum, particularly when borate concentration in the culture medium was $\geq 1 \%$ (14). Although several studies have reported that borate inhibited various postharvest fruit diseases and have elucidated the specific mode of action $(14,15)$, there is, to our knowledge, no information concerning the effect of borate on anthracnose of mango fruit or the effect of borate on pathogen ultrastructure.

The objectives of this study were to evaluate the effects of borate on germination, germ tube elongation, nuclear division, endocytosis, and ultrastructure of $C$. gloeosporioides conidia in vitro and to evaluate the effects of preharvest application of borate in the field for the control of anthracnose on mango flowers and fruit.

\section{Corresponding author: Shi-Ping Tian, E-mail: tsp@ibcas.ac.cn}

* The $\boldsymbol{e}$-Xtra logo stands for "electronic extra" and indicates that Figures 2 and 3 appear in color in the online edition.

Accepted for publication 12 September 2010.

doi:10.1094/PDIS-06-10-0437

(C) 2011 The American Phytopathological Society

\section{Materials and Methods}

Isolates and chemicals. Isolate C0011 was obtained from infected mango fruit exhibiting typical anthracnose symptoms. Cultures of isolate $\mathrm{C} 0011$ matched characteristics of $C$. gloeosporioides with sparse, cottony, white-to-pale gray mycelium that produced pink conidial masses in concentric rings on potato dextrose agar (PDA). Colonies grown on PDA plates at room temperature $\left(25 \pm 2{ }^{\circ} \mathrm{C}\right)$ produced cylindrical conidia $12-16 \times 6-8$ $\mu \mathrm{m}$. Amplification and sequencing of the ribosomal ITS1-5.8SITS2 region revealed maximum identity $(100 \%)$ with the sequence from C. gloeosporioides strain C1014.6 (GenBank accession no. EU149938; data not shown). The sequence of isolate C0011 was submitted to GenBank (accession no. HQ228999).

The pathogenicity of this single-conidium isolate was confirmed by wound inoculation of ripe mango fruit (unpublished data). For production of conidial suspensions, the isolate was grown on PDA at $25^{\circ} \mathrm{C}$. After 7 days culture on PDA, the conidia were removed from PDA plates by adding sterile-distilled water containing $0.05 \%$ ( $\mathrm{vol} / \mathrm{vol})$ Tween 80 and by gently scrubbing the culture surface with a sterile spatula. The suspension was filtered through four layers of sterile cheesecloth, and the concentration of the conidial suspension was determined with a hemacytometer.

Borate in the form of potassium tetraborate $\left(\mathrm{K}_{2} \mathrm{~B}_{4} \mathrm{O}_{7} \cdot 4 \mathrm{H}_{2} \mathrm{O}\right)$ was purchased from Sigma Chemical Co. (St. Louis, MO). The dyes DAPI (4',6-diamidino -2-phenylindole, dihydrochloride) and FM464 were supplied by Molecular Probes (Invitrogen, Carlsbad, CA). Glutaraldehyde, sodium cacodylate, osmium tetroxide, and Spurr resin were purchased from Polysciences, Inc. (Warrington, PA), and uranyl acetate and lead nitrate were purchased from Fisher Scientific International (Fairlawn, NJ).

Effect of borate on germination of $\boldsymbol{C}$. gloeosporioides conidia in vitro. The effects of borate on conidial germination and germ tube elongation of $C$. gloeosporioides were evaluated in potato dextrose broth (PDB) according to the method of Tian et al. (24). A borate solution of $15 \mathrm{mM}$ was chosen based on a preliminary study. The $\mathrm{pH}$ of PDB with $15 \mathrm{mM}$ borate was adjusted to 7.0 with $\mathrm{HCl}$ or was not adjusted $(\mathrm{pH} 9.2)$, and PDB without borate and at pH 7.0 served as the control. A suspension of $C$. gloeosporioides conidia at $1 \times 10^{7}$ conidia/ml was prepared, and $100 \mu \mathrm{l}$ of this suspension was added to $400 \mu \mathrm{l}$ of PDB with or without borate in $1.5-\mathrm{ml}$ centrifuge tubes. A $200-\mu \mathrm{l}$ volume was immediately re- 
moved from the centrifuge tube and placed on a sterile glass coverslip $(22 \times 22 \mathrm{~mm})$. The coverslips $(200 \mu \mathrm{l}$ in total $)$ were incubated at $100 \%$ relative humidity $(\mathrm{RH})$ at $25^{\circ} \mathrm{C}$. For this experiment and the other in vitro experiments described in this paper, the coverslips were placed in moisture chambers and randomly arranged in the incubator. Germination rate and germ tube elongation were determined by destructively examining three replicate coverslips per treatment after $4,6,8$, and $12 \mathrm{~h}$ of incubation. Determination of germination and germ tube length was based on examination of 100 conidia per coverslip (for germination) or 50 conidia per coverslip (for germ tube length) with a Zeiss Axioskop 40 microscope at $\times 250$ magnification. A conidium was recorded as germinated if the germ tube was at least half the length of the conidium. The experiment was performed three times (trials 1 to 3 ).

Effect of borate on nuclear division in C. gloeosporioides conidia in vitro. Conidial suspensions were prepared and conidia were incubated $\left(25^{\circ} \mathrm{C}\right.$ and $\left.100 \% \mathrm{RH}\right)$ in PDB with and without 15 $\mathrm{mM}$ borate $(\mathrm{pH} 7.0)$ on coverslips as described earlier. Nuclear division in the conidia was assessed after the conidia had been incubated without borate for $4,6,8$, or $12 \mathrm{~h}$ and after the conidia had been incubated with borate for 4, 6, 8, 12, 24, 48, 72, and $96 \mathrm{~h}$. For each time, three coverslips per treatment were destructively sampled, and 50 specimens were examined on each coverslip. Nuclear morphology was determined by staining with DAPI. Conidia were fixed for $15 \mathrm{~min}$ in a solution of $50 \mathrm{mM}$ potassium phosphate ( $\mathrm{pH} 7.0$ ), 0.2\% Triton X-100, and 5\% glutaraldehyde, and then were stained with DAPI at a final concentration of 1 $\mu \mathrm{g} / \mathrm{ml}$. Specimens were observed with a confocal microscope (TCS SP5, Leica, Bensheim, Germany). The experiment was performed twice (trials 1 and 2).

Effect of borate on conidial endocytosis in vitro. Conidial suspensions were prepared and conidia were incubated $\left(25^{\circ} \mathrm{C}\right.$ and $100 \% \mathrm{RH})$ in PDB with and without $15 \mathrm{mM}$ borate ( $\mathrm{pH} \mathrm{7.0)}$ on coverslips as described earlier. After 2 or $6 \mathrm{~h}$, three coverslips per treatment were destructively sampled. A stock solution of FM4-64 (10 $\mathrm{mM}$ in DMSO) was diluted in distilled $\mathrm{H}_{2} \mathrm{O}$ and then added to the conidia on the coverslip to make a final concentration of $1 \mu \mathrm{M}$ FM4-64. The dyed conidia were observed according to the method reported by Hoffmann and Mendgen (7). Fluorescence of the FM464 stained conidia was detected using a confocal microscope (Zeiss LSM 510 META LSCM). Serial optical sections were obtained every $10 \mathrm{~s}$ after dye application until the fluorescence reached saturation. At least 20 conidia were examined for each replicate coverslip, and the experiment was performed three times (trials 1 to 3 ).

Effect of borate on conidial ultrastructure. Conidial suspensions were prepared and conidia were incubated $\left(25^{\circ} \mathrm{C}\right.$ and $100 \% \mathrm{RH})$ in PDB with and without $15 \mathrm{mM}$ borate $(\mathrm{pH} 7.0)$ on coverslips as described earlier. After 2, 4, 6, and $8 \mathrm{~h}$, the conidia were fixed overnight in $3 \%$ glutaraldehyde in $0.1 \mathrm{M}$ sodium cacodylate buffer, $\mathrm{pH} 7.2$ (SCB), and then collected by centrifugation $\left(16,000 \times g\right.$ for $5 \mathrm{~min}$ at $\left.4{ }^{\circ} \mathrm{C}\right)$. Gels of 1 to $2 \mathrm{~mm}^{3}$ were prepared by adding $3 \%$ low-gelling-temperature agarose in SCB to the pellet. After thorough rinsing with $0.1 \mathrm{M} \mathrm{SCB}$, the gels were postfixed with $1 \%$ osmium tetroxide in $0.1 \mathrm{M} \mathrm{SCB}$ for $4 \mathrm{~h}$ at room temperature, and then dehydrated using a series of increasing acetone concentrations. The samples were embedded in Spurr resin. Ultrathin sections were obtained with a Leica ultramicrotome and were stained by soaking in $2 \%$ uranyl acetate for $15 \mathrm{~min}$. The sections were washed in double-distilled water, poststained in lead citrate for $1 \mathrm{~min}$, and finally washed again in double-distilled water. For each sample time, 20 conidia per treatment were examined with a JEOL 1230 transmission electron microscope at $80 \mathrm{kV}$. The experiment was performed twice (trials 1 and 2).

Effect of borate application on flower and postharvest disease control. Two field experiments were conducted in an orchard of mango (cv. Tai Nong 1) located in Lingshui County, Hainan Province. The trees (6 years old) had been selected and grown using best management practices without any fungicide spray. The first experiment concerned the effect of borate on infection of flowers by $C$. gloeosporioides and on fruit set. The two treatments ( \pm borate sprays) were arranged in a randomized complete block design, with two blocks and three trees per treatment per block. The trees were sprayed twice with a $15-\mathrm{mM}$ borate solution ( $\mathrm{pH}$ not adjusted) or with water (control) during flowering. The first spray was applied at $20 \%$ flowering and the second at $80 \%$ flowering, 7 to 10 days later. The borate solution or water was applied with an air-pulsed sprayer at 150 liters $\mathrm{ha}^{-1}$ according to commercial practices. Trees were sprayed to runoff, with approximately 8 liters per tree. Flowers were removed from the trees (50 flowers per tree) 7 days after the second spray, surface-sterilized for $30 \mathrm{~s}$ with $70 \%$ ethanol, rinsed in sterile distilled water, and cultured on PDA at room temperature for 72 to 96 h. If $C$. gloeosporioides grew from a flower, the flower was

\section{$4 \mathrm{~h}$}

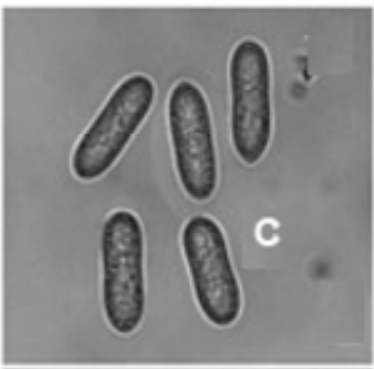

Borate

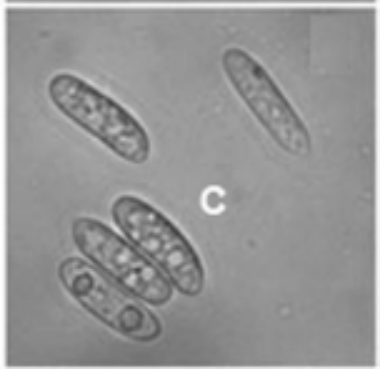

$6 \mathrm{~h}$
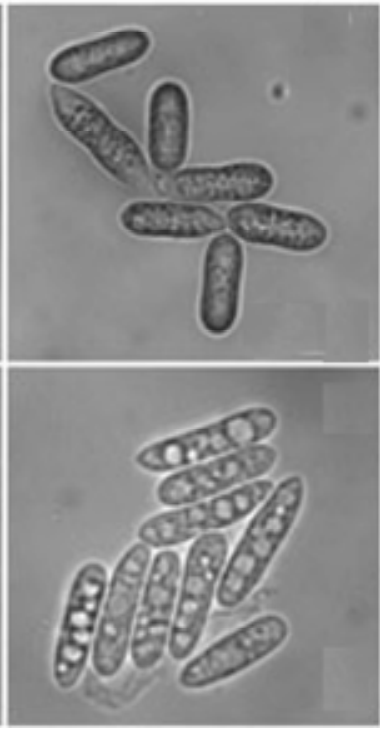

$8 \mathrm{~h}$
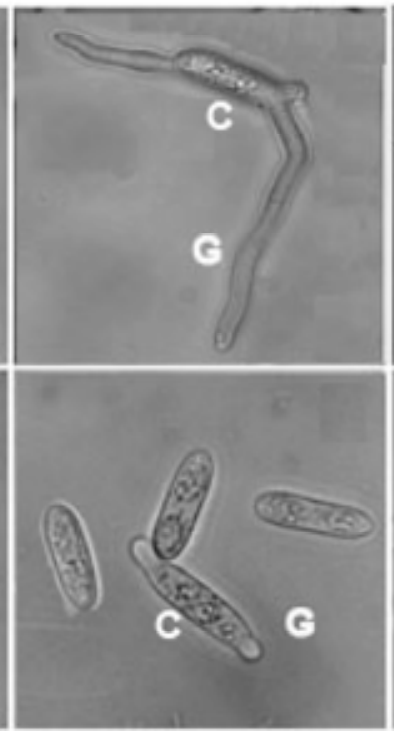

$12 \mathrm{~h}$

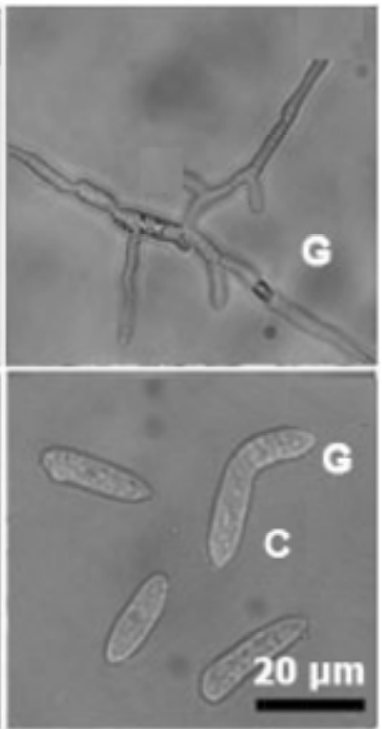

Fig. 1. Effect of borate on conidial germination and germ tube elongation of Colletotrichum gloeosporioides in vitro. Conidia were incubated in potato dextrose broth (pH 7.0 ) with $15 \mathrm{mM}$ borate or without borate (control) at $25^{\circ} \mathrm{C}$ for $4,6,8$, and $12 \mathrm{~h}$. C represents conidia and $\mathrm{G}$ represents germ tubes. 
recorded as infected. The number of fruit that set per branch was determined by examining five branches per tree 14 days after full bloom (20 days after the second spray); the five branches were different from those used to quantify flower infection.

The second field experiment used the same orchard and the same experimental design but different trees to evaluate the effect of preharvest borate sprays on postharvest disease development. Developing fruit were sprayed four times with water or a $15-\mathrm{mM}$ borate solution ( $\mathrm{pH}$ not adjusted) at 2-week intervals until harvest. The first spray was applied 45 days after fruit set. The fruit were harvested at commercial maturity. For each treatment, 90 fruit (15 per tree and 45 per block) were arbitrarily selected and kept at $25 \pm$ $2{ }^{\circ} \mathrm{C}$ and $75 \% \mathrm{RH}$ for 7 days. Anthracnose incidence was measured as the percentage of fruit with disease symptoms (5). Disease severity was assessed according to the scale described by Kefialew and Ayalew (8), where $1=$ no spots, $2=1$ to 3 spots, $3=4$ to 6 spots, $4=7$ to 12 spots, and $5=>12$ spots or $30 \%$ of the mango surface affected. A disease index (DI) was calculated using the

Table 1. Effect of $15 \mathrm{mM}$ borate on germination and germ tube elongation of Colletotrichum gloeosporioides conidia in vitro ${ }^{\mathrm{z}}$

\begin{tabular}{lcc}
\hline Treatment & Germination $(\%)$ & Germ tube length $(\boldsymbol{\mu m})$ \\
\hline Control $\mathrm{pH} 7.0$ & $96.4 \pm 8.5 \mathrm{a}$ & $140.0 \pm 20.6 \mathrm{a}$ \\
Borate $\mathrm{pH} \mathrm{7.0}$ & $30.5 \pm 4.4 \mathrm{~b}$ & $10.5 \pm 3.6 \mathrm{~b}$ \\
Borate $\mathrm{pH} \mathrm{9.2}$ & $15.5 \pm 3.0 \mathrm{c}$ & $6.5 \pm 2.4 \mathrm{~b}$ \\
\hline
\end{tabular}

${ }^{\mathrm{z}}$ Values are means \pm SD of three trials. The interaction between trial and treatment was not significant $(P=0.920)$, and data were combined. Means in a column followed by different letters are significantly different $(P<0.05)$ according to the Tukey-Kramer multiple comparison test. formula: DI $=\Sigma$ (severity level $\times$ number of fruit in the level $) \times$ $100 /$ (highest level $\times$ total number of fruit). Both field experiments were conducted in 2008 and repeated in 2009.

Statistical analysis. For all in vitro experiments, data were first subjected to Levene's test for homogeneity of variances and then to an analysis of variance (ANOVA). Before statistical analysis, percent data concerning conidia germination rate were arcsine transformed. The independent variables in the ANOVAs were borate treatment, trial, and the interaction between experiment and trial. The interaction between experiment and trial was not significant $(P>0.05)$ for any of these in vitro experiments (i.e., the results of different trials were similar), and the results presented are averages across all trials. When the effect of borate treatment was significant, means were separated by Tukey-Kramer multiple comparison analysis. SPSS 11.5 (SPSS Inc., Chicago, IL, USA) was used for all statistical analyses.

The field experiments for 2008 and 2009 were analyzed separately and are presented separately, i.e., year (trial) was not included as an independent variable in the analyses. Data for disease incidence were arcsine transformed before analysis. After the data were subjected to Levene's test for homogeneity of variances. The effects of borate treatment $( \pm)$ on flower infection, fruit set, and disease on harvested fruit were determined with Student's $t$ tests.

\section{Results}

Effect of borate on germination of $\boldsymbol{C}$. gloeosporioides conidia in vitro. In PDB without borate, the conidia of $C$. gloeosporioides began germinating $6 \mathrm{~h}$ after incubation at $25^{\circ} \mathrm{C}$ (Fig. 1). After $8 \mathrm{~h}$ in PDB without borate, nearly all of the conidia had germinated
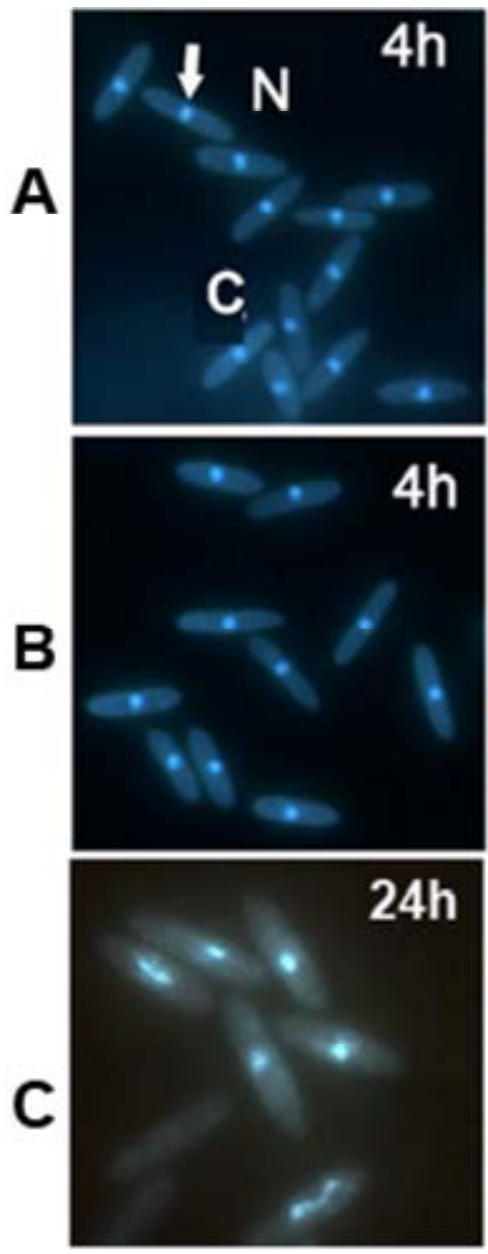
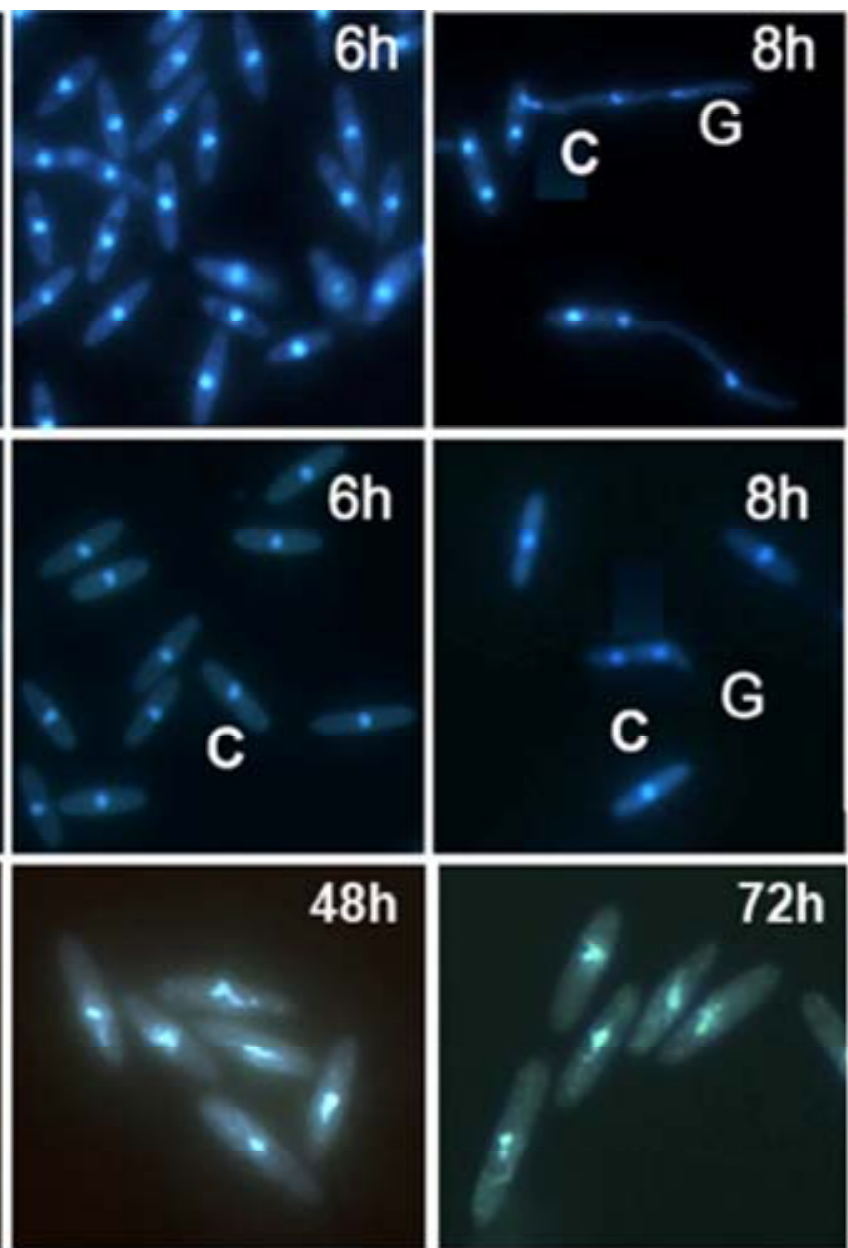

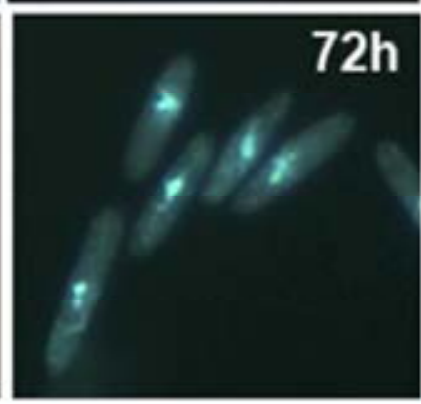

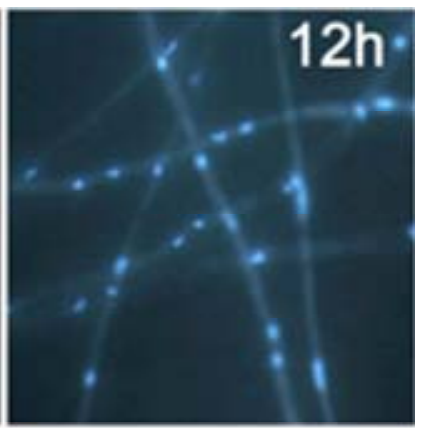
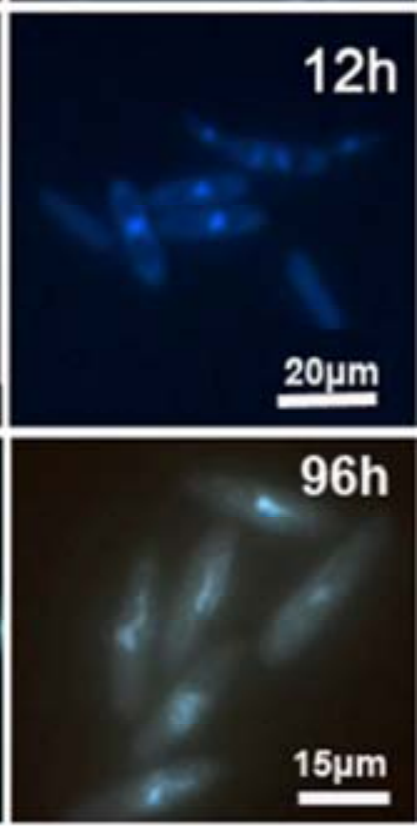

Fig. 2. Effect of borate on nuclear division in conidia of Colletotrichum gloeosporioides. Conidia were incubated at $25^{\circ} \mathrm{C}$ in $\mathrm{A}$, potato dextrose broth (PDB) without borate for $4,6,8$, and $12 \mathrm{~h}$ or in B and C, PDB containing $15 \mathrm{mM}$ borate for 4, 6, 8, 12, 24, 48, 72, and $96 \mathrm{~h}$. Conidia were then stained with DAPI and examined with a confocal microscope. Note that nuclear division was delayed by borate and that nuclei appeared degraded after prolonged incubation in borate. N, nucleus; C, conidia; G, germ tube. 
and had produced germ tubes about $140 \mu \mathrm{m}$ long (Fig. 1, Table 1). Germination and germ tube elongation were significantly inhibited by the addition of $15 \mathrm{mM}$ borate to the PDB (Fig. 1, Table 1), and the inhibition tended to be greater when $\mathrm{pH}$ of the borate-amended medium was not adjusted ( $\mathrm{pH}$ 9.2) than when it was adjusted to 7.0 (Table 1).

Effect of borate on nuclear division in C. gloeosporioides conidia. Similar results were obtained for both trials, and representative conidia were photographed. After 4 and $6 \mathrm{~h}$ of incubation in PDB without borate, each conidium contained only one nucleus, although the intensity of nuclear fluorescence was greater at $6 \mathrm{~h}$ than at $4 \mathrm{~h}$ (Fig. 2A). As incubation time increased above $6 \mathrm{~h}$ and the conidia germinated, the number of nuclei in conidia incubated in PDB without borate steadily increased. After $8 \mathrm{~h}$ in PDB without borate, almost all of the conidia had germinated, and there were four to six nuclei per conidium (Fig. 2A).

In PDB with $15 \mathrm{mM}$ borate $(\mathrm{pH} \mathrm{7.0)}$, the intensity of nuclear fluorescence did not increase between the fourth and sixth hour of incubation (Fig. 2B). After $8 \mathrm{~h}$ in PDB with borate, nuclear division was defective in most conidia (Fig. 2B). The nuclei were irregular in shape after $24 \mathrm{~h}$ in PDB with borate (Fig. 2B), and the nuclei appeared to be degraded after $96 \mathrm{~h}$ in PDB with borate (Fig. 2C).

Effect of borate on conidial endocytosis. Incubation in PDB with borate increased the time required for conidial uptake of FM4-64 stain (Fig. 3 and Table 2). This inhibition of endocytosis by borate was greater when the conidia had been incubated in borate for $6 \mathrm{~h}$ (Fig. 3C versus D) than for $2 \mathrm{~h}$ (Fig. 3A versus B) (Table 2).

Effect of borate on conidial ultrastructure. Results of both trials were similar, and representative micrographs are presented. Conidia incubated for $2 \mathrm{~h}$ in PDB without borate had normal plasma membranes, organized cytoplasm, and visible nuclei and mitochondria with well-defined envelopes (Fig. 4A). With pro- longed incubation in the absence of borate, numerous mitochondria were present in the cell periphery. The plasma membrane remained intact after $4 \mathrm{~h}$ (Fig. 4C), and Golgi apparatus, endoplasmic reticula, and septa appeared after $6 \mathrm{~h}$ (Fig. 4E).

After exposure to $15 \mathrm{mM}$ borate for $2 \mathrm{~h}$, the nucleus was visible but the conidia contained many vacuoles (Fig. 4B), and vacuole number increased after $4 \mathrm{~h}$ (Fig. 4D). After $6 \mathrm{~h}$ of exposure to borate, the cytoplasm appeared to be degraded and contained abnormal mitochondria. After exposure to borate for $8 \mathrm{~h}$, the cytoplasm had disintegrated and organelles had degraded (Fig. $4 \mathrm{H})$.

Effect of borate application for control of C. gloeosporioides on flowers and on fruit postharvest. The results of the independent field experiments in 2008 and 2009 were consistent. In both years of the first field experiment, treating the mango inflorescences with borate significantly decreased the percentage of flowers with anthracnose (Fig. 5A) and increased the number of fruit that set per branch (Fig. 5B) compared with the water-sprayed control. In both years of the second field experiment, the spraying of developing fruit in the field with

Table 2. Time required for Colletotrichum gloeosporioides conidia to take up and become saturated with FM4-64 as affected by prior treatment with $15 \mathrm{mM}$ borate or water (control) for 2 or $6 \mathrm{~h}^{\mathrm{z}}$

\begin{tabular}{lc}
\hline Treatment & FM4-64 uptake time $(\mathbf{s})$ \\
\hline Control $2 \mathrm{~h}$ & $50 \pm 5 \mathrm{c}$ \\
Borate $2 \mathrm{~h}$ & $70 \pm 6 \mathrm{~b}$ \\
Control $6 \mathrm{~h}$ & $45 \pm 5 \mathrm{c}$ \\
Borate $6 \mathrm{~h}$ & $180 \pm 20 \mathrm{a}$ \\
\hline
\end{tabular}

Values are means \pm SD of three trials. The interaction between trial and treatment was not significant $(P=0.970)$, and data were combined. Means in columns followed by different letters are significantly different $(P<0.05)$ according to the Tukey-Kramer multiple comparison test.

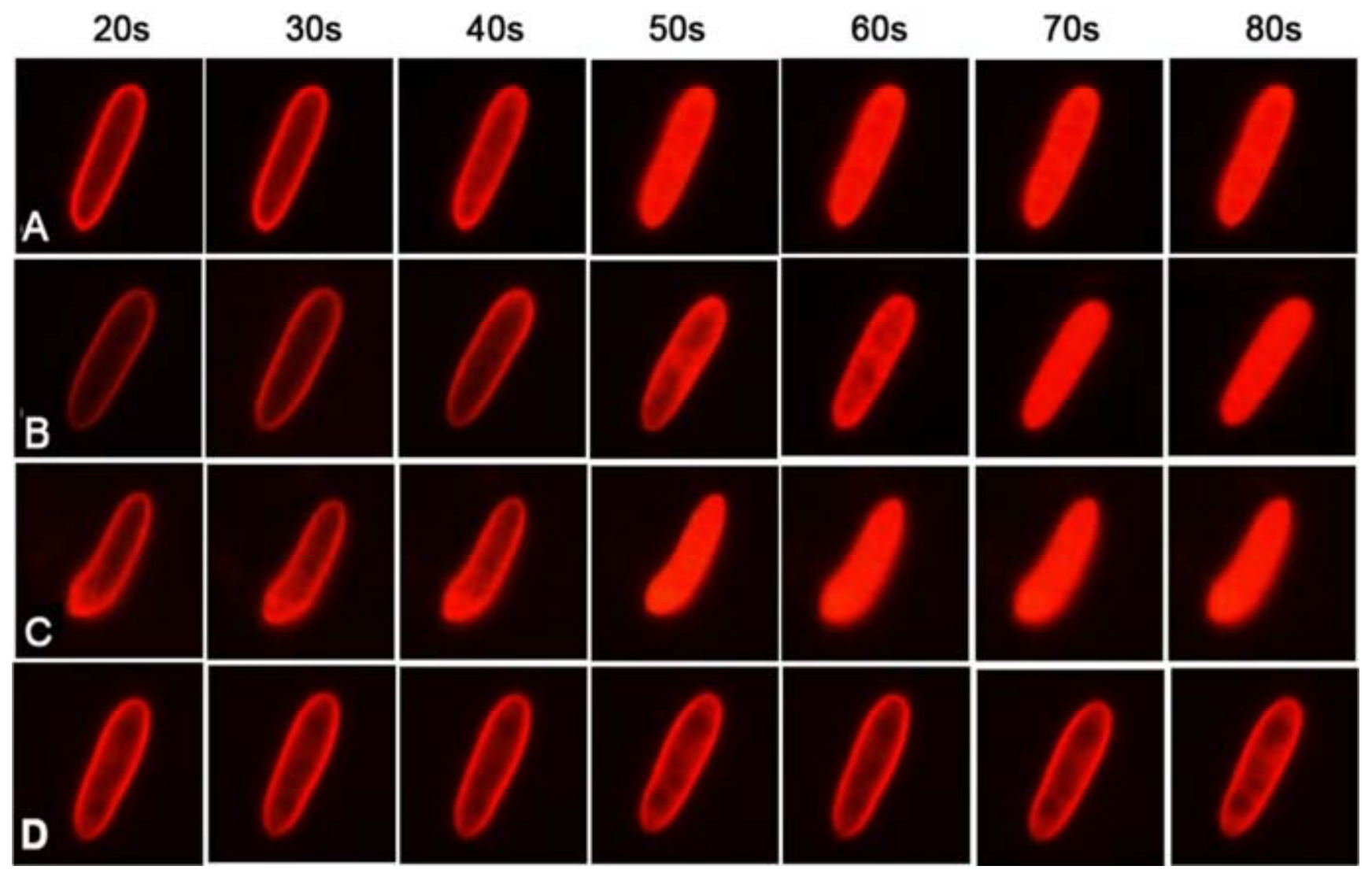

Fig. 3. Uptake of FM4-64 by conidia of Colletotrichum gloeosporioides as affected by borate. Conidia were incubated in potato dextrose broth (PDB) without borate for $\mathrm{A}, 2 \mathrm{~h}$ or C, $6 \mathrm{~h}$ or in PDB with $15 \mathrm{mM}$ borate for B, $2 \mathrm{~h}$ or D, $6 \mathrm{~h}$. After this incubation, the conidia were placed in FM4-64 for 20 to $80 \mathrm{~s}$ and then examined with a confocal microscope. 
borate significantly reduced the development of postharvest anthracnose (Fig. 6).

\section{Discussion}

As an essential plant micronutrient, boron is crucial for organelle development, fruit development, and seed set (23). Boron deficiency in mango can lead to a physiological disorder termed fruit pitting (19). In this study, borate significantly inhibited conidia germination and germ tube elongation of $C$. gloeosporioides in vitro, and application of borate in the field decreased anthracnose of mango flowers, increased fruit set, and reduced anthracnose of harvested mango fruit. The laboratory results suggest that the disease control in the field resulted from direct antifungal activity of borate against $C$. gloeosporioides. This is consistent with the reports that boron has antimicrobial activity and can be useful for the control of strawberry and grapevine diseases $(17,21)$.
The mode of action of borate against fungal pathogens is not well understood. In a previous study, we found that borate led to the production of reactive oxygen species (ROS) in the spores of Penicillium expansum and inhibited germination of those spores (14). In the current study, $C$. gloeosporioides conidia treated with 15-mM borate exhibited defective nuclear division. Defective nuclear division can lead to DNA damage, restricted cytokinesis, branch formation, and cell death (3). Effects on nuclear division are not unique to boron, however, because a number of new systemic fungicides have also been reported to act as inhibitors of DNA synthesis or as antimitotic compounds $(1,18)$. Our results indicate that borate also impairs endocytosis in conidia. Endocytosis, as a key process for hyphal tip growth, serves multiple functions including the delivery of biosynthetic and hydrolytic enzymes as well as membrane and wall components to the hyphal apex or the growing bud. Fuchs et al. (2) thought that endocytosis
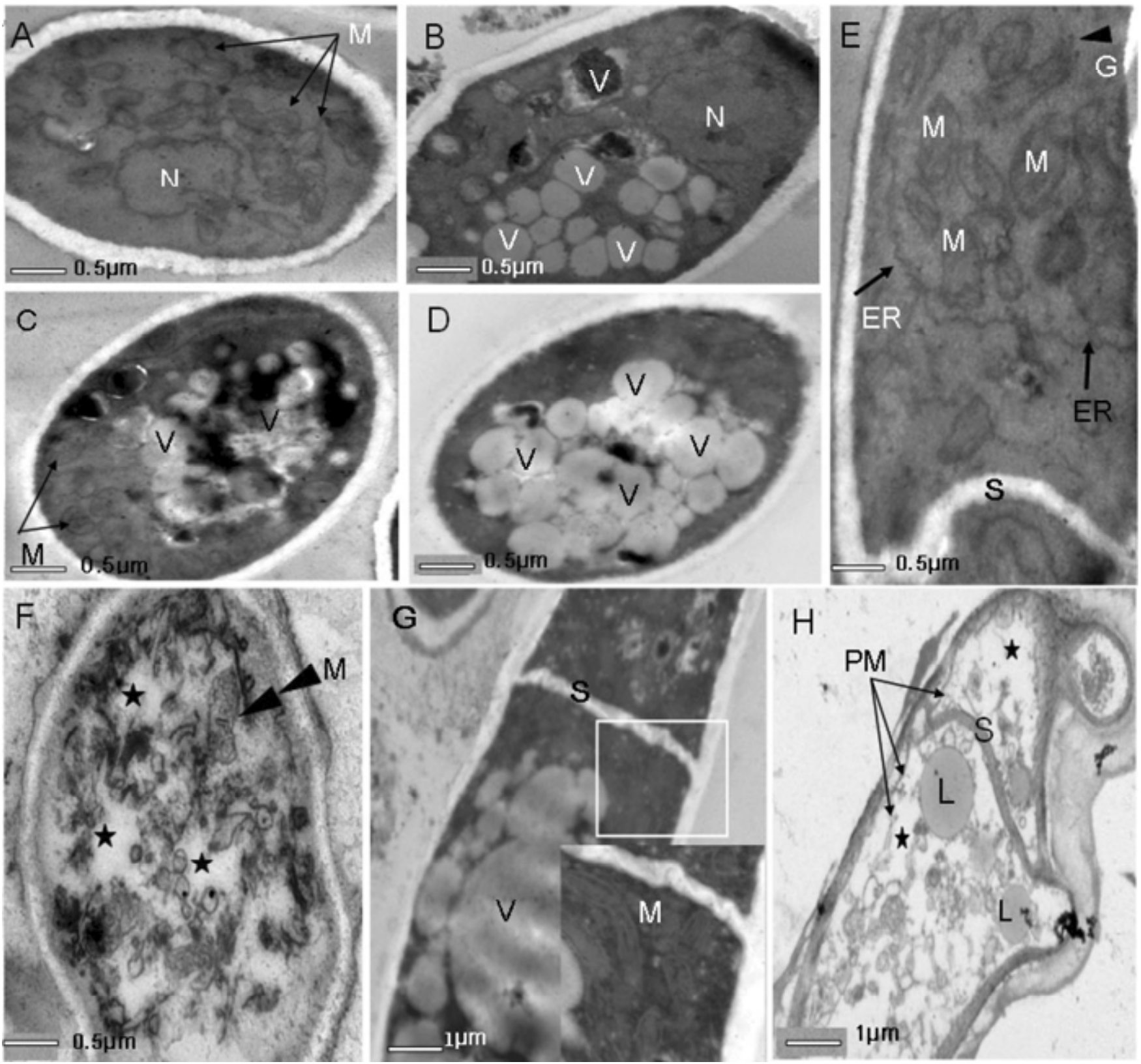

Fig. 4. Transmission electron microscopy (TEM) micrographs of Colletotrichum gloeosporioides conidia that were incubated in potato dextrose broth (PDB) without borate for A, $2 \mathrm{~h}, \mathrm{C}, 4 \mathrm{~h}, \mathrm{E}, 6 \mathrm{~h}$, and $\mathbf{G}, 8 \mathrm{~h}$, or in PDB with borate for B, $2 \mathrm{~h}, \mathrm{D}, 4 \mathrm{~h}, \mathbf{F}, 6 \mathrm{~h}$, and $\mathbf{H}, 8 \mathrm{~h}$. In the absence of borate, the cytoplasm appears normal and mitochondria (M), Golgi equivalents (G, arrowhead), endoplasmic reticula (ER, arrows), and nucleus $(\mathrm{N})$ are normal. After $2 \mathrm{~h}$ of borate treatment (B), vacuoles (V) have developed, and after 6 $\mathrm{h}$ of borate treatment $(\mathrm{F})$, the cytoplasm appears degraded, has developed empty spaces (asterisks), and contains abnormal mitochondria (double arrowheads). After $8 \mathrm{~h}$ of borate treatment $(\mathrm{H})$, the cytoplasm has disintegrated and organelles have degraded; plasmolysis, invaginated plasma membrane (arrow), and many voids (asterisks) are evident. S: septum; L: lipid bodies. 

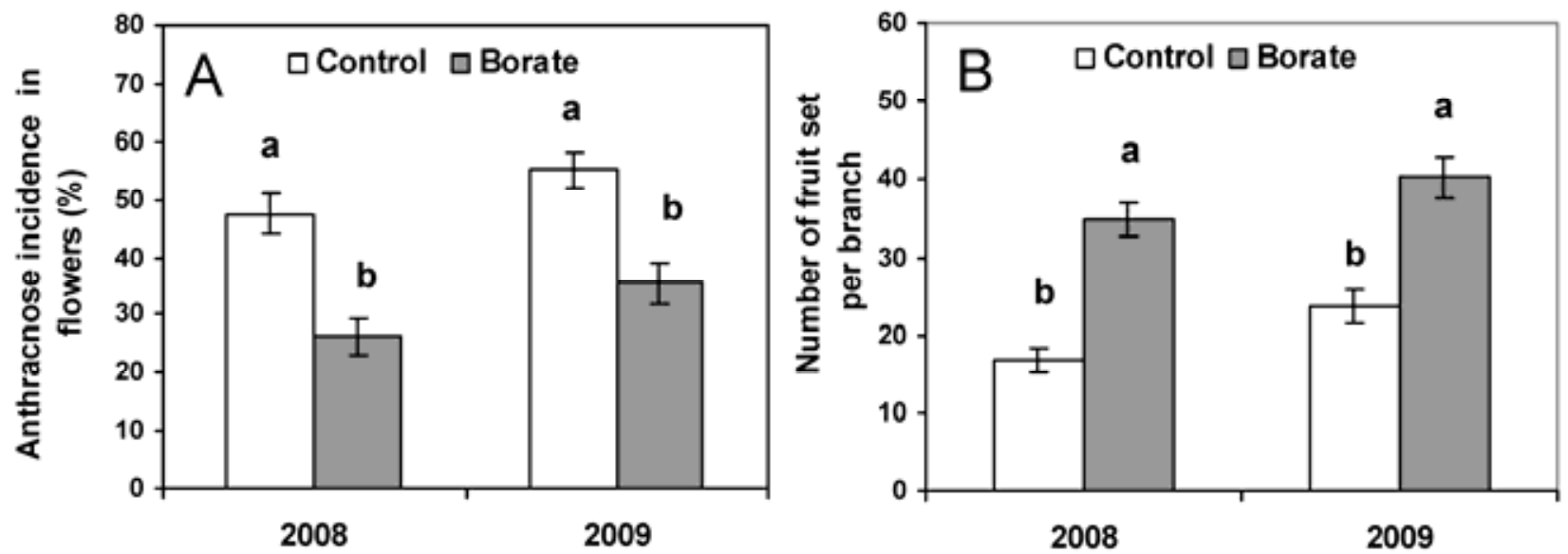

Fig. 5. Effect of a borate spray on $\mathbf{A}$, incidence of anthracnose caused by Colletotrichum gloeosporioides on mango flowers, and $\mathbf{B}$, number of fruit set per mango branch. This field experiment was conducted in 2008 and repeated in 2009. Vertical bars indicate standard deviations, and values within a year followed by a different letter are significantly different according to Student's $t$ test at $P<0.05$.
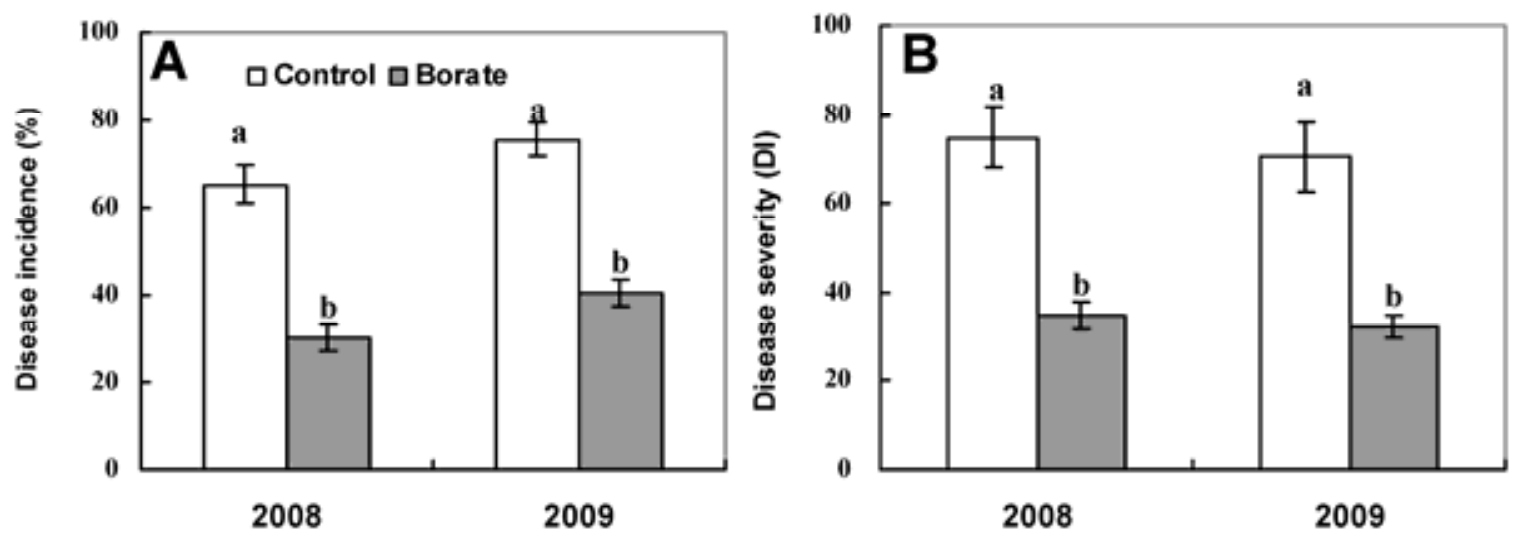

Fig. 6. Effect of preharvest borate sprays or water sprays (control) in a mango orchard on postharvest development of anthracnose caused by Colletotrichum gloeosporioides in 2008 and 2009. Mango fruit were harvested and stored at room temperature for 7 days before they were assessed for A, anthracnose incidence, and B, anthracnose severity. $\mathrm{DI}=\Sigma$ (severity level $\times$ number of fruit in the level) $\times 100 /$ (highest level $\times$ total number of fruit). Vertical bars indicate standard deviations, and values within a year followed by a different letter are significantly different according to Student's $t$ test at $P<0.05$.

was essential not only for recognition of the host plant at the start of pathogenesis but also for conidia germination. Our study also provides evidence that borate alters the ultrastructure of $C$. gloeosporioides conidia, leading to disintegration of the cytoplasm and degradation of mitochondria. Similar ultrastructural reactions of fungal spores to antifungal compound have been recently reported. Avis et al. (1) documented membrane retraction, undulation, and invagination, loss of membrane integrity, cytoplasmic leakage, and cell rupture in Fusarium sambucinum after exposure to $\mathrm{AlCl}_{3}$ and $\mathrm{Na}_{2} \mathrm{~S}_{2} \mathrm{O}_{5}$. Borate disrupted the cell membrane of Botrytis cinerea, eventually leading to leakage of cytoplasmic materials and the death of the fungal pathogen (15). Because the antifungal mechanisms of borate appear to be complex, further research should focus on the molecular basis of borate activity in C. gloeosporioides.

Borate is effective in controlling gray mold of table grape caused by $B$. cinerea (15) and blue mold on apple fruit caused by $P$. expansum (14). In this study, we report that preharvest application of borate at a concentration of $15 \mathrm{mM}$ could effectively enhance the fruit setting rate per branch and significantly reduce anthracnose disease incidence of mango fruits in storage. These results suggest that borate applications in the field can control postharvest fruit decay. Further research is necessary to investigate the effect of borate in combination with other treatments for integrated control of postharvest diseases.

In conclusion, our findings demonstrate that borate inhibited the germination of $C$. gloeosporioides conidia in vitro and reduced anthracnose on flowers and on harvested mango fruit when applied to trees in the field. The possible mechanisms in the inhibition of C. gloeosporioides by borate might involve delayed nuclear division, impaired endocytosis, and damaged ultrastructure.

\section{Acknowledgments}

This study was supported by National Basic Research Program of China ( 973 Project, 2006CB1019007) and by The Ministry of Science and Technology of China (2006BAD22B02).

\section{Literature Cited}

1. Avis, T. J., Rioux, D., Simard, M., Michaud, M., and Tweddell, R. J. 2009. Ultrastructural alterations in Fusarium sambucinum and Heterobasidion annosum treated with aluminum chloride and sodium metabisulfite. Phytopathology 99:167-175.

2. Fuchs, U., Hause, G., Schuchardt, S., and Steinberg, G. 2006. Endocytosis is essential for pathogenic development in the corn smut fungus Ustilago maydis. Plant Cell 18:2066-2081.

3. Genet, J. 1996. Nuclear division, nuclear distribution and cytokinesis in filamentous fungi. Indian Acad. Sci. 75:351-360.

4. Girvan J. W. 1986. Borate algaecide and fungicide. U.S. Patent: 4,594, 091.

5. Govender, V., Korsten, L., and Sivakumar, D. 2005. Semi-commercial evaluation of Bacillus licheniformis to control mango postharvest diseases in South Africa. Postharv. Biol. Technol. 38:57-65.

6. Hervieux, V., Yaganza, E. S., Arul, J., and Tweddell, R. J. 2002. Effect of organic and inorganic salts on the development of Helminthosporium solani, the causal agent of potato silver scurf. Plant Dis. 86:1014-1018.

7. Hoffmann, J., and Mendgen, K. 1998. Endocytosis and membrane turnover in the germ tube of Uromyces fabae. Fungal Genet. Biol. 24:77-85.

8. Kefialew, Y., and Ayalew, A. 2008. Postharvest biological control of anthracnose (Colletotrichum gloeosporioides) on mango (Mangifera indica). Postharv. Biol. Technol. 50:8-11.

9. Kim, Y., Brecht, J. K., and Talcott, S. T. 2007. Antioxidant phytochemical 
and fruit quality changes in mango (Mangifera indica L.) following hot water immersion and controlled atmosphere storage. Food Chem. 105:1327-1334.

10. Loomis, W. D., and Durst, R. W. 1992. Chemistry and biology of boron. BioFactors 3:229-239.

11. Martínez-Romero, D., Serrano, M., Bailén, G., Guillén, P., Valverde, J. M., Castillo, S., Fuentes, M., and Valero, D. 2008. The use of a natural fungicide as an alternative to preharvest synthetic fungicide treatments to control lettuce deterioration during postharvest storage. Postharv. Biol. Technol. 47:54-60.

12. Mecteau, M. R., Arul, J., and Tweddell, R. J. 2002. Effect of organic and inorganic salts on the growth and development of Fusarium sambucinum, a causal agent of potato dry rot. Mycol. Res. 106:688-696.

13. Mills, A. A. S., Platt, H. W., and Hurta, R. A. R. 2004. Effect of salt compounds on mycelial growth, sporulation and spore germination of various potato pathogens. Postharv. Biol. Technol. 34:341-350.

14. Qin, G. Z., Tian, S. P., Chan, Z. L., and Li, B. Q. 2007. Crucial role of antioxidant proteins and hydrolytic enzymes in pathogenicity of Penicillium expansum. Mol. Cell Proteomics 6:425-438.

15. Qin, G. Z., Zong, Y. Y., Chen, Q. L., Hua, D. L., and Tian, S. P. 2010. Inhibitory effect of boron against Botrytis cinerea on table grapes and its possible mechanisms of action. Int. J. Food Microbiol. 138:145-150.

16. Rezanka, T., and Sigler, K. 2008. Biologically active compounds of semimetals. Phytochemistry 69:585-606.

17. Rolshausen, P. E., and Gubler, W. D. 2005. Use of boron for the control of
Eutypa dieback of grapevines. Plant Dis. 89:734-738.

18. Ruge, E., Korting, H. C., and Borelli, C. 2005. Current state of threedimensional characterisation of antifungal targets and its use for molecular modelling in drug design. Int. J. Antimicrob. Ag. 26:427-441.

19. Sharma, R. R., and Singh, R. 2009. The fruit pitting disorder-A physiological anomaly in mango (Mangifera indica L.) due to deficiency of calcium and boron. Sci. Hortic. 119:388-391.

20. Silimela, M., and Korsten, L. 2006. Evaluation of pre-harvest Bacillus licheniformis sprays to control mango fruit diseases. Crop Prot. 26:14741481.

21. Singh, R., Sharma, R. R., and Tyagi, S. K. 2007. Pre-harvest foliar application of calcium and boron influences physiological disorders, fruit yield and quality of strawberry (Fragaria $\times$ ananassa Duch.). Sci. Hortic.Amsterdam 112:215-220.

22. Strong, P. L. 2001. Boric acid and inorganic borate pesticides. Handbook of Pesticide Toxicology, 2nd ed. pp. 1429-1437.

23. Tanaka, M., Wallace, I. S., Takano, J., Roberts, D. M., and Fujiwara, T. 2008. NIP6; 1 is a boric acid channel for preferential transport of boron to growing shoot tissues in Arabidopsis. Plant Cell 20:2860-2875.

24. Tian, S. P., Fan, Q., Xu, Y., and Jian, A. L. 2002. Effects of calcium on biocontrol activity of yeast antagonists against the postharvest fungal pathogen Rhizopus stolonifer. Plant Pathol. 51:352-358.

25. Zheng, X. L., Tian, S. P., Gidley, M. J., Yue, H., and Li, B. Q. 2007. Effects of exogenous oxalic acid on ripening and decay incidence in mango fruit during storage at room temperature. Postharv. Biol. Technol. 45:281-284 